Topological and functional aspects of the proton conductor, $F_{0}$, of the Escherichia coli ATP-synthase

\author{
H. U. SCHAIRER, J. HOPPE, W. SEBALD, and P. FRIEDL
}

Department of stoffwechselregulation, GBF - Gesellschaft für

Biotechnologische Forschung mbH., Mascheroder Weg 1, D-3300 Braunschweig-Stöckheim, Federal Republic of Germany

(Received 5 July 1982)

The isolated $\mathrm{H}^{+}$conductor, $\mathrm{F}_{0}$, of the Escherichia coli ATP-synthase consists of three subunits, $a, b$, and c. $\mathrm{H}^{+}$-permeable liposomes can be reconstituted with $F_{0}$ and lipids; addition of $F_{1}$-ATPase reconstitutes a functional ATP-synthase. Mutants with altered or missing $F_{0}$ subunits are defective in $\mathrm{H}^{+}$conduction. Thus, all three subunits are necessary for the expression of $\mathrm{H}^{+}$conduction. The subunits $a$ and $b$ contain binding sites for $F_{1}$. Computer calculations, cross-links, membrane-permeating photo-reactive labels, and proteases were used to develop tentative structural models for the individual $F_{0}$ subunits.

ATP-synthases catalyze the proton-motive-force-dependent phosphorylation of ADP in oxidative phosphorylation and photophosphorylation. Inversely, hydrolysis of ATP via the ATP-synthase is coupled to the formation of a proton-motive force. Both reactions are inhibited by dicyclohexylcarbodiimide (DCCD). The enzymes occur in remarkably conserved form in prokaryotic and eukaryotic cells. They are composed of two parts, a membrane-integrated part $F_{0}$, rendering the membrane proton-permeable, and a membrane-associated part $F_{1}$, bearing ATPase activity. The functions of $F_{0}$ and of $F_{0}$ subunits were examined by a variety of different methods: isolation of $F_{0}$, reconstitution of biological activities, isolation of $\mathrm{F}_{0}$-mutants, elucidation of their structural alterations, and characterization of the functional implications. The structural features of individual $F_{0}$ subunits were investigated by determination of the primary structure, computer calculations of the secondary structure, cross-links, proteases, and photo-reactive labels.

\title{
Methods
}

The preparation of $F_{1}, F_{1} F_{0}, F_{0}$, membranes, $F_{1}$-depleted membranes, and antibodies against subunits was performed as described previously (Vogel \& Steinhart, 1976; Friedl et al., 1979; Friedl \& Schairer, 1981; Friedl et al., 1981). The constitution of strains and construction of plasmids are described elsewhere (Hansen et al., 198I; Hansen \& von Meyenburg, 1980; Gunsalus et al., 1982; Friedl et al., 1981; Friedl et al., 1980); plasmid pOM 11-1 contains the structural gene of subunit $a$ on a HindIII-Aval fragment cloned in PBR322 (Michelsen O, unpublished). 
Assays of $\mathrm{F}_{1}$ binding, $\mathrm{H}^{+}$conduction, and ATP-dependent $\mathrm{H}^{+}$ translocation were performed as described (Sebald et al., 1982; Friedl et al., 1980), as well as polyacrylamide-gel electrophoresis (Friedl et al., 1979) and silver-staining of gels (Merril et al., 1980). Predictions of secondary structure and membrane-permeating segments were done as described previously (Chou \& Fasman, 1978; Maxfield \& Scheraga, 1976; Robson \& Suzuki, 1976; Nagano, 1977; von Heijne, 1981).

\section{Proteolytic treatment of $F_{0}$-subunits in $F_{I}$-depleted membranes}

$\mathrm{F}_{1}$-depleted membranes were prepared from an Escherichia coli overproducer (obtained from $\mathrm{K}$. von Meyenburg). Membranes (5 $\mathrm{mg} / \mathrm{ml})$ were incubated in buffer $(100 \mathrm{mM}$ Tris/ $\mathrm{HCl}, \mathrm{pH} 7.8,5 \mathrm{mM}$ $\mathrm{MgCl}_{2}$ ) for $60 \mathrm{~min}$ at $37^{\circ} \mathrm{C}$ with proteases at ratios (w/w) of 1:1000, $1: 100$, and 1:10. After addition of protease-inhibitor phenylmethylsulfonylfluoride (PMSF) to $1 \mathrm{mM}$, membranes were washed twice with buffer and submitted to dodecylsulfate-gel electrophoresis. The protein bands were visualized by the silver-staining procedure.

\section{Cross-linking of $F_{O}$ subunit b from Escherichia coli}

Isolated ATP-synthase from Escherichia coli dissolved $1 \mathrm{mg}$ per $0.2 \mathrm{ml}$ in buffer $(50 \mathrm{mM} \mathrm{N}$-methylmorpholine, $\mathrm{pH} 8,100 \mathrm{mM} \mathrm{KCl,} 2$ $\mathrm{mM} \mathrm{MgCl}_{2}, 0.2 \mathrm{mM}$ EGTA, $0.2 \mathrm{mM}$ PMSF, $25 \mathrm{mM}$ Aminooxid WS 35, $20 \%$ methanol) was incubated in the dark with $5 \mathrm{mM}$ fluoronitrophenylazide for $60 \mathrm{~min}$ at room temperature. Thereafter the reactive nitrene was generated by illumination at $360 \mathrm{~nm}$ for $10 \mathrm{~min}$ at $0^{\circ} \mathrm{C}$. Proteins were separated electrophoretically on $0.7-\mathrm{mm}$-thick dodecylsulfate gels, and were then transferred electrophoretically onto nitrocellulose sheets (Towbin et al., 1979). The sheets were incubated with specific rabbit IgG directed against subunit $b$. Bound IgG was visualized after reaction with fluorescein-conjugated goat antirabbit IgG under u.v. light.

\section{Results and Discussion}

\section{$F_{1} F_{O}$ and $F_{0}$ preparations}

The Escherichia coli ATP-synthase has been purified in large quantities by extracting membranes with the zwitterionic detergent Aminoxid WS35 and subsequent chromatography of the extract on DEAE-Sepharose (Friedl et al., 1979). SDS/gel electrophoresis of the purified enzyme revealed 8 subunits: in addition to the five subunits of $F_{1}, \alpha-\varepsilon, 3$ polypeptides, $a, b$, and $c$, are found (Fig. 1), with the apparent mol. wts. of 24000,19000 , and 8500. After reintegration into liposomes the enzyme is active in ATP-dependent proton translocation to more than 90\% (Table 1). $F_{0}$ was isolated from the purified ATP-synthase (Friedl \& Schairer, 1981). Fig. 1 shows that $F_{0}$ consists of the three subunits $a, b$, and $c$. The catalytic activities of $F_{0}$ could be determined after integration into liposomes (Table 1). $F_{0}$ catalyzed an electro-impelled proton flux which can be inhibited by DCCD or by binding of $F_{1}$. Binding of $F_{1}$ restores the ATP-dependent proton-translocation. 


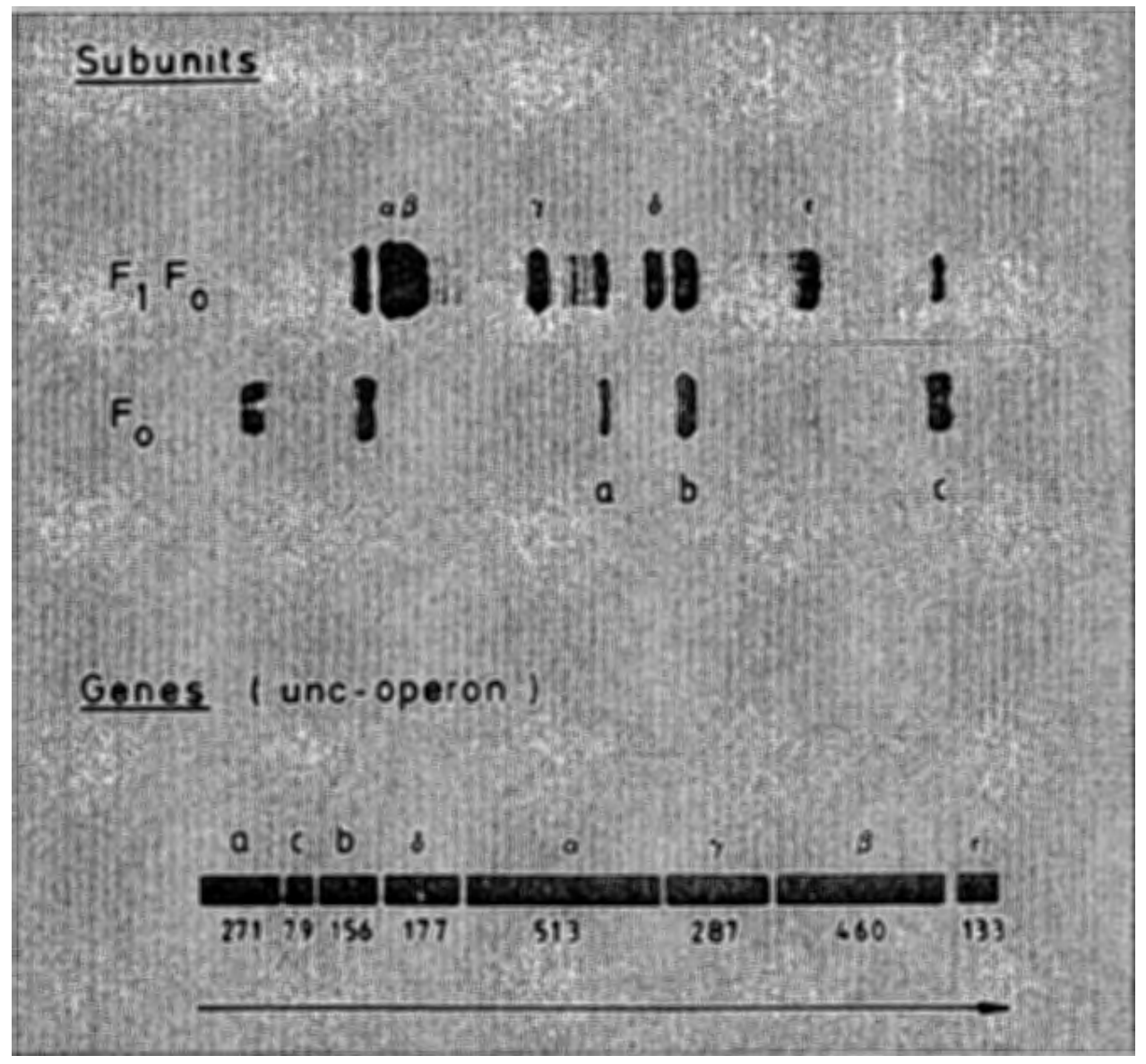

Fig. 1. Subunits and genes of the Escherichia coli ATP-synthase. SDS/polyacrylamide-gel electrophoresis was performed as described in methods. The order of the genes in the unc operon and the correlation of genes with ATP-synthase subunits was established genetically and by nucleotide sequence analysis. The numbers below the genes indicate the number of amino acid residues in the subunit polypeptides.

\section{$F_{0}$-mutants}

Genetic studies of the $E$. coli ATP-synthase started with the isolation and characterization of mutants defective in oxidative phosphorylation (for review see Downie et al., 1979). The genes coding for the polypeptides of the ATP-synthase are organized in the unc-operon (Fig. 1). The complete DNA sequence of the operon has been determined (Gay \& Walker, 1981; Nielsen et al., 1981; Kanazawa et al., 1981). Mutants with an altered $F_{0}$-subunit $a, b$, or $c$ are defective in proton conduction and ATP-dependent proton translocation. This indicates that in vivo all three subunits are necessary for these functions. In order to correlate certain functions to the different $F_{0}$ subunits, mutant strains were constructed lacking one or two of the $\mathrm{F}_{0}$ subunits. 
Table 1. Activities of $\mathrm{F}_{1} \mathrm{~F}_{0}$ and $\mathrm{F}_{0}$ from Escherichia coli.

Membranes, $\mathrm{F}_{1}$-depleted membranes, $\mathrm{F}_{1} \mathrm{~F}_{0}, \mathrm{~F}_{0}$, and proteoliposomes were prepared and the assays were performed as described in 'Materials and Methods'.

\begin{tabular}{|c|c|c|c|}
\hline \multirow[t]{2}{*}{ Fraction } & \multicolumn{2}{|c|}{$\begin{array}{l}\text { Electro-impelled } \\
\mathrm{H}^{+} \text {conduction }\end{array}$} & \multirow{2}{*}{$\begin{array}{l}\text { ATP-dependent } \\
\mathrm{H}^{+} \text {translocation } \\
\text { Fluorescence test }\end{array}$} \\
\hline & $\begin{array}{c}\mathrm{pH}-\mathrm{electrode} \\
\mathrm{nmo} 1 \cdot \mathrm{min}^{-1} \cdot \mathrm{mg}^{-1}\end{array}$ & $\begin{array}{l}\text { F1uorescence test } \\
\mathrm{U}_{\mathrm{f} 1} \cdot \mathrm{mg}^{-1}\end{array}$ & \\
\hline Membranes & - & - & 130 \\
\hline $\begin{array}{l}\mathrm{F}_{1} \text {-depleted } \\
\text { membranes }\end{array}$ & 44 & 65 & - \\
\hline \multicolumn{4}{|c|}{ Liposomes with } \\
\hline $\begin{array}{l}\mathrm{F}_{1} \mathrm{~F}_{0} \\
\mathrm{~F}_{0}+\mathrm{F}_{1} \\
\mathrm{~F}_{0} \\
\mathrm{~F}_{0}+\mathrm{DCCD}\end{array}$ & $\begin{array}{r}5 \\
41 \\
870 \\
2\end{array}$ & $\begin{array}{r}16 \\
151 \\
2565 \\
24\end{array}$ & $\begin{array}{r}2330 \\
1910 \\
-\end{array}$ \\
\hline
\end{tabular}

Table 2 shows that for the expression of proton conduction all three subunits of $F_{0}$ are necessary. On the other hand subunit $a$ or subunit $b$ alone can bind $F_{1}$, whereas subunit $c$ cannot. Binding of $F_{1}$ by these subunits does not reconstitute DCCD-sensitivity of the ATPase activity or ATP-dependent proton translocation.

Table 2. Activities of $\mathrm{F}_{0}$ in unc-mutants lacking individual $\mathrm{F}_{0}$ subunits

\begin{tabular}{lccccc}
\hline Strain & F $_{0}$ subunits & $\mathrm{H}^{+}$conduction & $\mathrm{F}_{1}$ binding \\
\hline $\mathrm{A} 1$ & a & b & c & + & + \\
DG10/6 & a & b & & - & + \\
CM2080 (1og) & & b & c & - & + \\
AM12 & a & & c & - & + \\
CM1470 + p0M11-1 & a & & & - & + \\
CM1470 + pRPG51 & & b & & - & + \\
CM2080 (stat) & & & c & - & - \\
CM 1470 & & & & - & -
\end{tabular}

Strains: Al wild type; CM1470 and CM2080 deletion mutants; the presence of subunit $b$ depends on growth phase ( $10 \mathrm{~g}=10 \mathrm{garithmic}$, stat = stationary phase); AM12 and DG10/6, polar mutants; pOM11-1, plasmid with structural gene for subunit a; pRPG51, plasmid with structural gene for subunits $b$ and $\delta$. Tests were performed as described in 'Materials and Methods'. 


\section{Structure of $F_{0}$}

The stoichiometry of $F_{0}$ seems to be unusual. Homogeneous labelling of the proteins with radioactive precursors revealed a ratio for $a: b: c$ of 1:2:10 (Foster \& Fillingame, 1982). The high number for subunit $c$ explains the observed strong negative complementation in $\mathrm{C}^{+} / \mathrm{C}^{-}$heterozygotes (Friedl et al., 1980). But it is difficult to propose a reasonable model for $F_{0}$. The DNA sequence of the unc-operon combined with partial amino acid sequencing provides the primary structure of the $F_{0}$ subunits. Fig. 2 shows a computer printout for the $F_{0}$ subunits with predictions for the secondary structure (Chou \& Fasman, 1978; Maxfield \& Scheraga, 1976; Robson \& Suzuki, 1976; Nagano, 1977) and for the membrane-permeating segments (von Heijne, 1981). The proposal for the DCCD-binding subunit $c$ is the 'hairpin' model (Sebald \& Hoppe, 1981) with two hydrophobic segments spanning the membrane and a central polar loop at the membrane surface. The DCCD-binding aspartyl-residue 61 is located in the lipid phase. The replacement of this amino acid by glycine or asparagine leads to an $\mathrm{F}_{0}$ defective in $\mathrm{H}^{+}$conduction (Hoppe et al., 1980b; J. Hoppe, unpublished). DCCD-resistant mutants originate from substitutions of isoleucine 28 by threonine or valine (Hoppe et al., 1980a). In the hairpin model this isoleucine is located in the vicinity of the DCCD-reactive aspartyl residue. Circulardichroism measurements support the high content of alpha-helical secondary structures of this subunit (Sebald \& Hoppe, 1981).

Subunit $b$ consists of 156 amino acids and is mainly hydrophilic. Only the 33 amino acids of the $N$ terminus form a hydrophobic domain sticking in the membrane, the greatly alpha-helical polar moiety being exposed to the cytoplasm.

Subunit $a$ is the largest $F_{0}$ subunit. The sequence of 271 amino acids shows seven hydrophobic sequences of about 20-25 residues. According to the model, they are spanning the membrane, and the $N$-terminal region of 40 amino acids could be exposed to the cytoplasm. Due to its highly hydrophobic character no protein-chemical characterization has been performed so far.

Lipophilic membrane-permeating photoreactive labels were used to modify specifically amino acid residues located in the membrane. All three subunits get labelled with trifluoromethyliodophenyldiazirine. The characteristic labelling patterns of subunits $c$ and $b$ support the above-presented models for these subunits (J. Hoppe, unpublished). The characterization of water-exposed segments was achieved by protease treatment of $F_{1}$-depleted membranes from an ATP-synthaseoverproducing strain (obtained from K. von Meyenburg). Fig. 3 shows that subunit $C$ was only marginally degraded even at high protease concentrations, and subunit a was only partially affected at high concentrations of subtilisin and V 8 protease. In contrast subunit $b$ was very protease-sensitive, indicating its accessibility from the water phase. Remarkably, chymotrypsin produced a membrane-bound cleavage product lacking 20 residues of the polar $C$ terminus. Proton conduction of $F_{0}$ and binding of $F_{1}$ were not affected, but ATPdependent proton conduction was abolished (J. Hoppe, unpublished). 


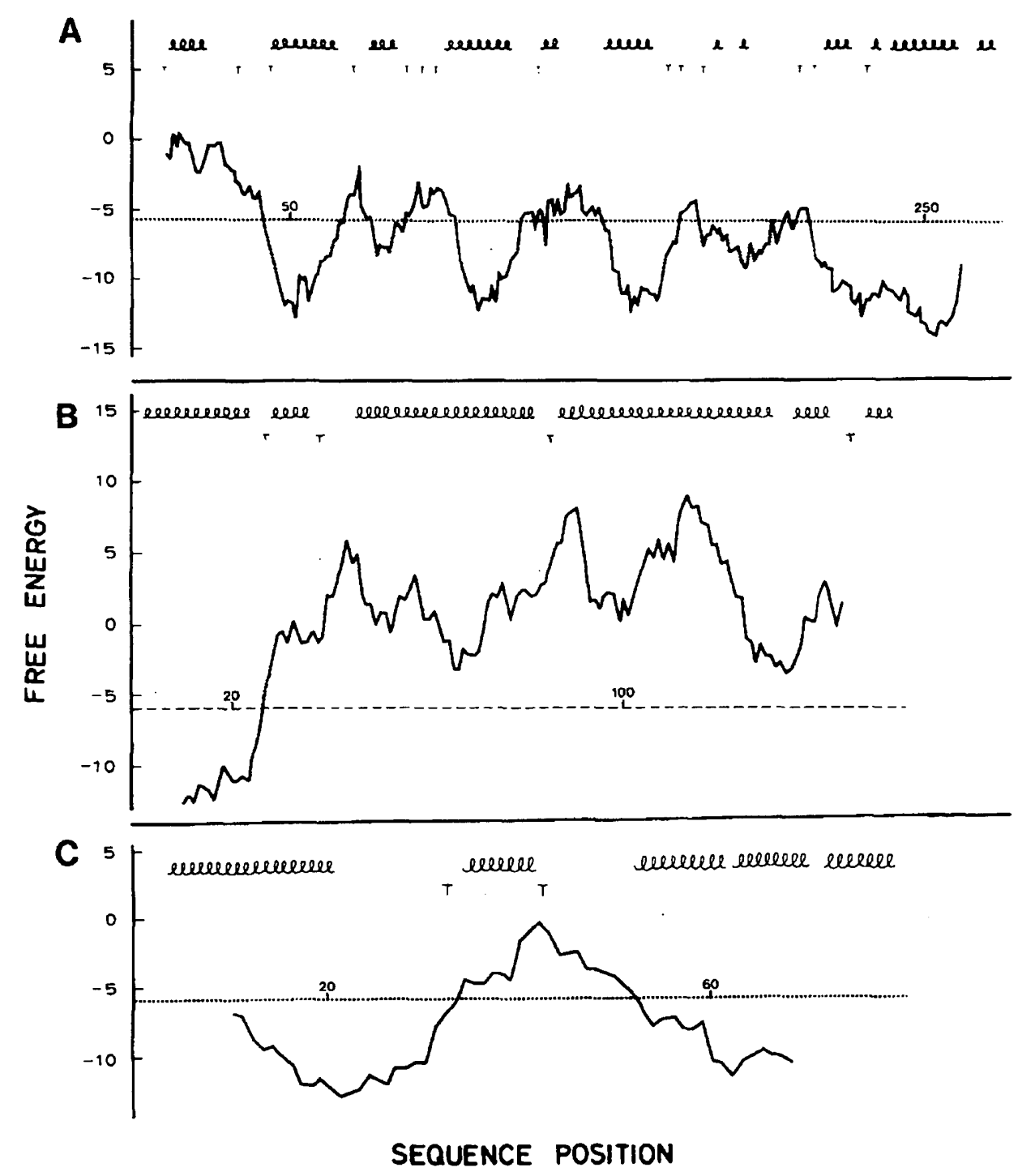

Fig. 2. Prediction of secondary structures and membrane-permeating segments in $F_{0}$ subunits of Escherichia coli. Alpha-helical segments (200) and $B$-turns ( $T$ ) were consistently calculated applying four different prediction methods. The free-energy gains during a transition from a random coil in water to an alpha-helix in the membranes were calculated for all amino acid sequence positions. The area below the dotted lines indicates increased probability for a location in the lipid bilayer, and the numbers on the dotted lines give the sequence position of the amino acids. Plots for subunits a (A), $b$ (B), and $c$ (C). 


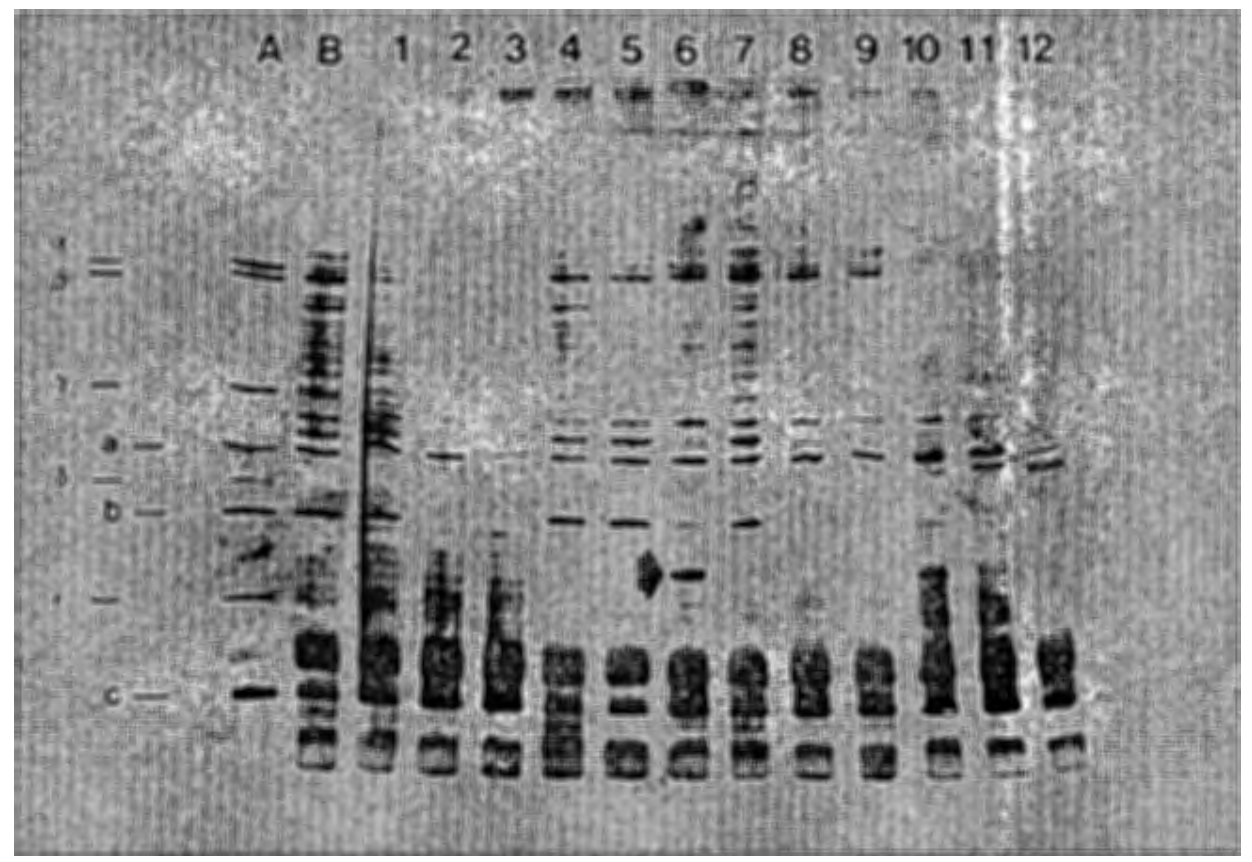

Fig. 3. Proteolytic treatment of $F_{0}$ subunits in $\mathrm{F}_{1}$-depleted membranes. $\mathrm{F}_{1}$-depleted membranes were prepared from an Escherichia coli overproducer (obtained from $X$. von Meyenburg). Lane A shows separated $F_{1} F_{0}$, and lane $B$, separated $F_{1}$-depleted membranes. The protease concentrations increase in the samples from left to right for V8 ( 1 anes 1-3), chymotrypsin (4-6), trypsin (7-9), and subtilisin $(10-12)$. The arrow indicates the digestion product obtained with chymotrypsin.

Cross-links of ATP-synthase subunits were obtained using the bivalent electrophilic and photoreactive reagent azidonitrophenylfluoride. The results of the subsequent analysis by SDS/gel electrophoresis, blotting, and immunochemical staining are shown in Fig. 4. The most prominent cross-link product is $b-b$, indicating a $b$-dimer in the ATP-synthase. Small amounts of additional subunit $b$ cross links were observed which are tentatively assigned to cross-links with the subunits $a, c, \alpha$, and $B$. This suggests that subunit $b$ has multiple contacts with other subunits, indicating its location in the center of the ATP-synthase.

The results presented are in accordance with the prediction made for the structure of the $F_{0}$ subunits. Further elucidation of the structure of $F_{0}$ as well as of $F_{1}$ will be brought about by the use of monoclonal antibodies, peptide chemistry, and electron microscopy. 


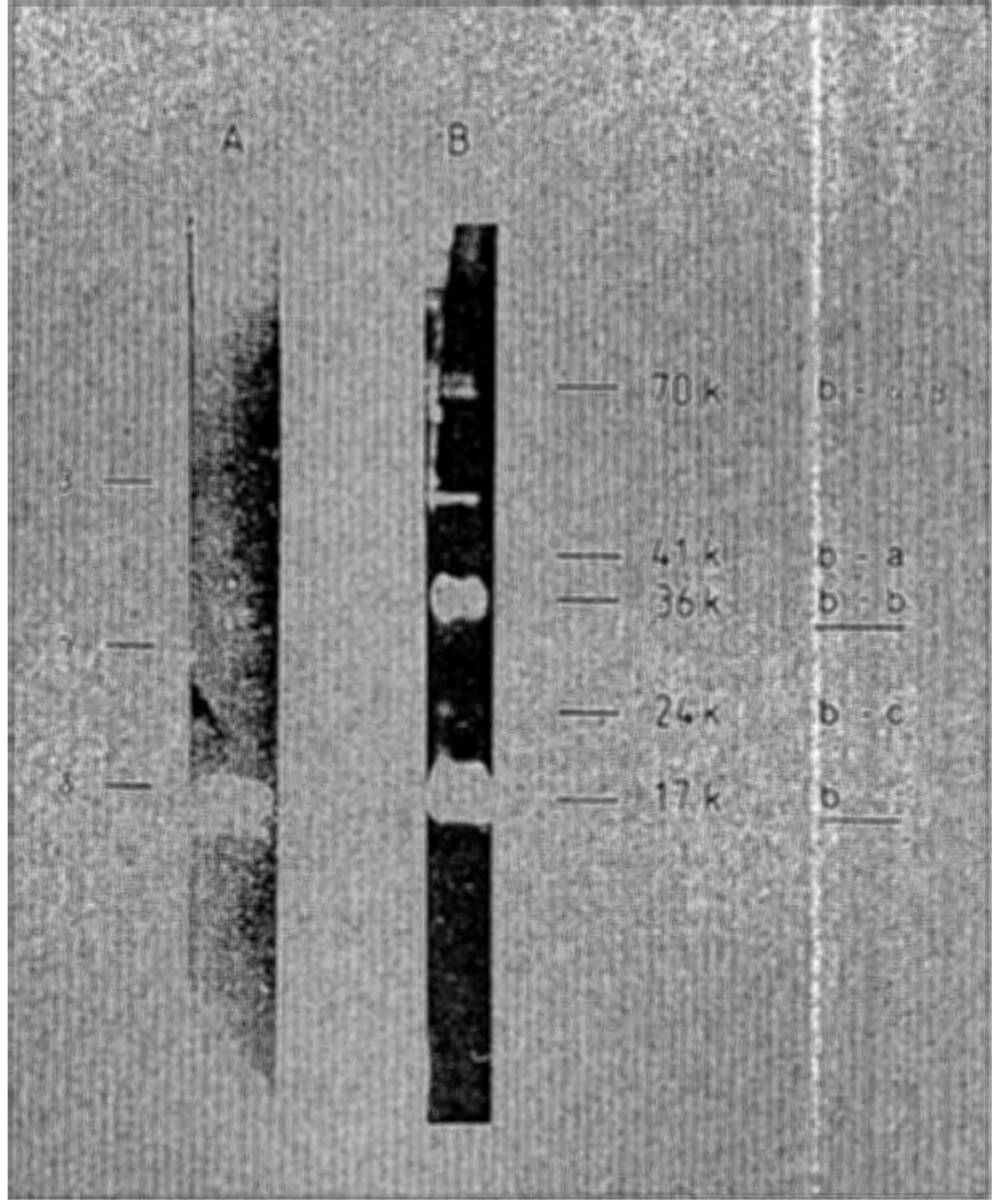

Fig. 4. Cross-1inking of $F_{0}$-subunit $b$ from Escherichia coli. Isolated $\mathrm{F}_{1} \mathrm{~F}_{0}$ was cross-1inked with fluoro-nitrophenylazide and subjected to SDS/polyacrylamide-gel electrophoresis, and the separated products were transferred to nitrocellulose and stained for antigenic material as described in 'Materials and Methods'. Lane A shows the identification of subunit $b$ in the absence of cross-linking. Lane $B$ demonstrates the appearance of cross-links containing subunit $b$. The positions of subunits $\beta, \gamma$, and $\delta$, which were separated in paralle1, are indicated.

\section{References}

Chou PY \& Fasman GD (1978) Adv. Enzymol. Relat. Areas Mol. Biol. 47, 45-148.

Downie JA, Gibson F \& Cox GB (1979) Ann. Rev. Biochem. 48, 103130 . 
Foster DL \& Fillingame RH (1982) J. Biol. Chem. 257, 2009-2015. Fried1 P \& Schairer HU (1981) FEBS Lett. 128, 261-264.

Fried1 P, Friedl C \& Schairer HU (1979) Eur. J. Biochem. 100, 175-180.

Fried1 P, Fried1 C \& Schairer HU (1980) FEBS Lett. 199, 254-256. Fried1 P, Bienhaus G, Hoppe J \& Schairer HU (1981) Proc. Nat1. Acad. Sci. U.S.A. 78, 6643-6646.

Gay JN \& Walker JE (1981) Nucl. Acids Res. 9, 3919-3926. Gunsalus RP, Brusilow WSA \& Simoni RD (1982) Proc. Nat1. Acad. Sci. U.S.A. 79, 320-324.

Hansen $F$ \& von Meyenburg $K(1980)$ in Mechanistic studies of DNA Replication and Genetic Recombination (Alberts B \& Fox CF, eds), ICN-UCLA Symposia on Molecular and Cellular Biology 19, 137-159, Academic Press, New York.

Hansen FG, Nielsen J, Riise E\& von Meyenburg K (1981) Mol. Gen. Genet. 183, 463-472.

Hoppe J, Schairer HU \& Sebald W (1980a) Eur. J. Biochem. 112, 17-24.

Hoppe J, Schairer HU \& Sebald W (1980b) FEBS Lett. 109, 107-111. Kanazawa H, Mabuchi K, Kayano T, Noumi T, Sekiya \& Futai M (1981) Biochem. Biophys. Res. Commun. 103, 613-620.

Maxfield FR \& Scheraga HA (1976) Biochemistry 15, 5138-5153. Merril CR, Goldman D, Sedman SA \& Ebert MH (1980) Science 211 , 1437-1438.

Nagano K (1977) J. Mo1. Biol. 109, 251-274.

Nielsen J, Hansen J, Hoppe J, Friedl P \& von Meyenburg K (1981) Mol. Gen. Genet. 184, 33-39.

Robson B \& Suzuki E (1976) J. Mol. Biol: 107, 327-356.

Sebald W \& Hoppe J (1981) in Current Topics in Bioenergetics (Sanadi DR, ed), vol 12, pp 1-57, Academic Press, New York.

Sebald W, Friedl P, Schairer HU \& Hoppe J (1982) Annal. New York Acad. Sci., in press.

Towbin H, Staehelin T \& Gordon J (1979) Proc. Natl. Acad. Sci. U.S.A. 76, 4350-4354.

von Heijne G (1981) Eur. J. Biochem. 120, 275-278.

Vogel G \& Steinhart R (1976) Biochemistry 15, 208-216. 